\title{
MANAGING EXTREME AGRICULTURE RISKS IN BRAZIL
}

\author{
DIEGO ARIAS, PEDRO A. VIEIRA \& PAULO M. MENDES \\ World Bank, Empresa Brasileira de Pesquisa Agropecuaria \& Ministry of Agriculture of Brazil.
}

\begin{abstract}
The agricultural sector is strategic for Brazil's economy and society. Nevertheless, the fluctuation in national agriculture GDP, which reaches $1 \%$ per year on average, and can reach more than $3 \%$ in some cases, indicates the weakness of disaster risk management in the sector. This study identified that Brazil has some successful public policies and programs dedicated for disaster risk management in the agriculture sector that serve as reference for other developing countries. However, they are mainly focused on risk mitigation. Disaster risk response and transfer mechanisms for agriculture, especially insurance, are still underdeveloped in relation to other similar emerging economies such as Argentina and Mexico. Furthermore, this study points out to the importance of managing extreme agriculture risks in an integrated fashion, as there are clear interrelationships among the main risks facing the agriculture sector of Brazil. Finally, the results of this study also strongly suggest that there is a lack of integration of existing federal-level public policies and programs dedicated to agricultural disaster risk management in Brazil, which constraints the reduction of systemic losses at the national level.

Keywords: agriculture policies, agriculture risks, brazil agriculture, disaster risk, extreme risks, risk management, risk strategies.
\end{abstract}

\section{INTRODUCTION}

The agriculture sector of Brazil faces a large number of risks linked to the productive process, which has led to substantial losses to the country in the past years. An adequate and integrated management of those risks can leave farmer incomes less exposed to losses, benefiting the sector and the country as a whole. Therefore, given the always-present resource limitation, it is important to maximize the economic returns of agriculture risk management actions. Brazil built important agriculture risk management policies and programs, but there are several signs that it is possible to improve their efficiency and effectiveness with more coordination and a prioritization in the treatment of gaps and opportunities.

The objective of this work was to undertake a rapid and integrated review of agriculture risk management in Brazil, identifying gaps and opportunities for improving current public policies and programs at the federal level in the short and long term. Beyond potential improvements in specific agriculture risk management policies and programs, an improved coordination and integration of current tools can reduce the risk profile of the sector. In this context, the authors, within the context of a collaboration between the World Bank, the Brazilian Agriculture Research Company (Embrapa) and the Ministry of Agriculture of Brazil (MAPA), put forward a rapid an integrated review of agriculture risk management in Brazil. The rapid review had the following phases: (i) national electronic survey with sector stakeholders; (ii) analysis of the risk perception of agriculture sector experts; (iii) literature review; and (iv) validation of results from stakeholder institutions. This analysis intends to build a systemic vision of agriculture risk management and had the support of different institutions linked to the agriculture sector.

Extreme agriculture sector risks can be grouped by production, market and enabling environment risks. According to the typology set by the World Bank, extreme production risks refer to the actual production and includes weather, fire, animal and plant health, and any unexpected change in the management of the farm and/or its natural resources (such as 
changes in regulation and/or technical assistance for example). Extreme market risks include mainly significant changes in output and/or input prices, unexpected changes to access to credit, to markets, including external markets. Finally, extreme enabling environment risks include events that change the context of policies and institutions (changes in the legal/regulatory framework, sector institutions, interpretation of laws and regulations), including logistics and infrastructure (Table 1).

Agriculture production is one of the main pillars of the Brazilian economy. The participation of the primary agriculture sector to total GDP is close to 6\% in Brazil and agribusiness represents $23 \%$ of GDP, being the backbone of an important value added chain that represents $32 \%$ of total employment. Beyond the multiplier effect in income and employment generation, historically, the agriculture sector has contributed significantly to the trade balance of Brazil. In the past 10 years, the volume of agroexports grew more than $200 \%$ and the trade balance $468 \%$, resulting in agroexports reaching US $\$ 100$ billion in 2013, representing almost $42 \%$ of total exports from Brazil. Brazil is the largest exporter of coffee, sugar, orange juice and meat (cow and chicken); the second largest in maize and soy (grains, oil and flower); and being one of the leaders in pork meat and cotton among other rural products.

Although the agriculture sector is one of the engines of the Brazilian economy, it is also more volatile in economic terms. This volatility has impacts in the country in terms of: (i) the

Table 1: Main extreme agriculture risks in Brazil.

\begin{tabular}{|c|c|c|}
\hline $\begin{array}{l}\text { EXTREME RISK } \\
\text { GROUP }\end{array}$ & RISK & EXAMPLES OF HAZARDS \\
\hline \multirow[t]{4}{*}{$\begin{array}{l}\text { PRODUCTION } \\
\text { RISK }\end{array}$} & Weather and Fires & $\begin{array}{l}\text { Prolonged droughts, frosts, excess rain, strong } \\
\text { winds and floods. }\end{array}$ \\
\hline & Animal Health & $\begin{array}{l}\text { Foot and mouth disease, BSE (mad cow dis- } \\
\text { ease), Newcastle, etc. }\end{array}$ \\
\hline & Plant Health & $\begin{array}{l}\text { Introduction of new pests and diseases } \\
\text { (ex.: lagarta Helicoverpa armigera). }\end{array}$ \\
\hline & $\begin{array}{l}\text { Natural Resources } \\
\text { and Production } \\
\text { Management }\end{array}$ & $\begin{array}{l}\text { Changes in water rights/allocation, in technical } \\
\text { assistance, in control of regulations, in labor } \\
\text { availability. Sudden mismanagement of natural } \\
\text { resources (ex. drought in RS) like incorrect } \\
\text { decisions on soil and water management. }\end{array}$ \\
\hline \multirow[t]{2}{*}{ MARKET RISK } & $\begin{array}{l}\text { Trade (price of } \\
\text { inputs and outputs) } \\
\text { and credit }\end{array}$ & $\begin{array}{l}\text { Substantial changes in output or input prices, in } \\
\text { exchange rates, in interest rates, in credit terms. }\end{array}$ \\
\hline & International trade & $\begin{array}{l}\text { Unexpected closing of export markets and } \\
\text { changes in the access of imported inputs. }\end{array}$ \\
\hline \multirow[t]{2}{*}{$\begin{array}{l}\text { ENABLING } \\
\text { ENVIRONMENT } \\
\text { RISK }\end{array}$} & $\begin{array}{l}\text { Infrastructure and } \\
\text { logistics }\end{array}$ & $\begin{array}{l}\text { Strikes at the port, closing of roads, railways, } \\
\text { waterways, and changes in the incentives for } \\
\text { storage. }\end{array}$ \\
\hline & $\begin{array}{l}\text { Regulatory, Policy } \\
\text { or Institutional } \\
\text { Framework }\end{array}$ & $\begin{array}{l}\text { Changes in laws/regulations (environmental, } \\
\text { labor, inputs, land), changes in the approach of } \\
\text { public institutions or the change in interpreta- } \\
\text { tion of existing laws and regulations. }\end{array}$ \\
\hline
\end{tabular}


multiplier effect and its corresponding dependency in other agriculture subsectors; (ii) the importance of the sector in fiscal revenues; (iii) the impact in the increase of domestic prices, in particular food products; and (iv) the importance of the sector in rural incomes. Agriculture sector volatility is produced by different risk groups that can result in extreme economic losses.

Brazil loses annually, on average, $1 \%$ of the value of agriculture production due to extreme events. Following a simple methodology to calculate agriculture losses as a function of extreme events, we find that extreme events do not just cause losses in agriculture production, but also, in those given years of extreme events, agriculture GDP growth is negative. In the years that the largest losses have occurred, 2004-2006 and 2012-2013, they had been related to severe droughts. In 2004-2006 the impact was in the south and southeast region of the country, while in 2012-2013 the reduction in production was related to the extreme drought in the northeast region. It is important to consider that loss values from extreme losses could be higher when taking into account forgone producer income of those agriculture products and/or regions with limited or lack of access to risk mitigating mechanisms. Beyond the estimated losses due to extreme weather events, the agriculture sector of Brazil suffers other losses due to risks such as unexpected changes in the regulatory framework, in the management of production and natural resources and other risks that are difficult to quantify.

The consequences from extreme agriculture sector risks vary by region, by type of farmer and by value chain. Agriculture in the northeast region, saw losses of up to $90 \%$ of grain production in areas without irrigation in 2012, and had negative growth in the last three years, with average losses of three work-days/year for rural families due to low production and water shortages according to De Nys et al. [1]. Family farming, given they reduced access to financial risk transfer instruments, suffer disproportionally more from extreme risks that affect their revenues. This has contributed towards the increase in rural poverty in the State of Sao Paulo in precisely the poorest regions of the country, as well as towards the reduction of one standard deviation in the yields of permanent and temporary crops, reducing up to an estimated 42,000 jobs according to MBAgro [2]. Finally, certain risks can have severe consequences in entire value chains. For example, the foot and mouth disease outbreak in Mato Grosso do Sul and in Parana in 2005 closed the meat export market to Russia, which was restored only 28 months after according to Nogueira e Doliveira [3]. The reduction in meat exports during that period was one-third of the total exported volume, having a significant impact in farmer income and in also in the competitive position of the value chain in international markets.

For the federal government, as well as for the state governments, extreme agriculture risks imply important fiscal expenditures. From the public expenditure side, events that impact the agriculture sector income, such as natural disasters, pests and diseases, significant fluctuations in food, labor, input and energy prices, as well as agriculture production per sea, mean that agriculture emergency expenditures at all levels of government can have important impacts for the economy as a whole. The federal government estimates that, only for the northeast, the response to the extreme drought of the last few years has resulted in additional public expenditures of approximately $\mathrm{R} \$ 17$ billions according to the Senate of the Brazilian Congress [4]. The risks also have an impact in fiscal revenues. From the side of fiscal revenues, a reduction in $10 \%$ of the Brazilian production of soy can result in an annual reduction of $\mathrm{R} \$ 1.6$ billion in fiscal revenues, equivalent to $16 \%$ of the annual budget of MAPA (Fig. 1). If losses would occur in various agriculture products at the same time, the fiscal impact, in revenues and expenditures, would be significant. 


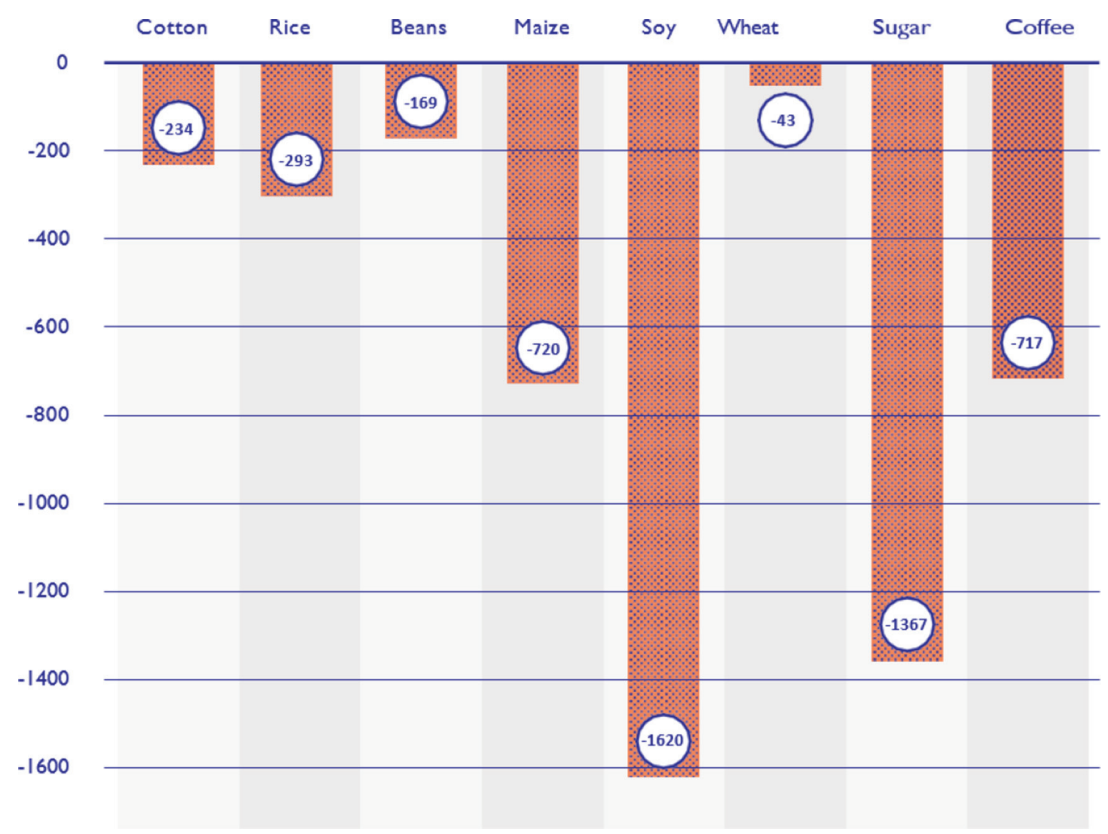

Figure 1: Loss in fiscal revenues due to a reduction in $10 \%$ in agriculture production ( $\mathrm{R} \$$ millions) (MB Agro [2]).

\section{METHODOLOGY}

There are several methodologies and approaches to doing an integrated agriculture sector risk review. In the past few years, OECD proposed a holistic conceptual framework for agriculture risk management and the World Bank developed a methodology for evaluating in an integrated manner the risks of agriculture supply chains [5]. Recently, the World Bank has been using this latter methodology for an integrated assessment to support government in the prioritization of agriculture risk management public investments and actions.

A rapid review methodology was developed by the authors in order to be able to map the main public policies and programs and identify the challenges and opportunities to improve extreme agriculture risk management. Usually, the risk evaluation includes risk quantification, prioritization, analysis of capacities and the search of solutions to manage systemic risks. However, given the richness of previous information, studies and assessments before this study in Brazil, the decision was to undertake a rapid review based on consultations with more than 100 specialists and an electronic survey sent out to more than 5000 representatives of the sector, of which $10 \%$ responded. The work was backed up by an empirical evaluation of those risks in two states (Bahia and Paraiba) and in one Municipality (Piquet Carneiro, Ceara). The results of the consultations of the specialists and of the electronic survey were compared with the results of a literature review of the most recent studies in risk evaluation in the country and with the main public policies and programs, according to budget and coverage, dedicated to mitigating, transferring and responding to extreme agriculture risks. After they were categorized, the preliminary results were presented to various stakeholders related to the agriculture sector of Brazil and the implementation of public policies for validation and improvement of the results. 
In order to reduce the complexity of the work, only events with farm-level impacts were evaluated due to limited resources, in particular time, only farm-level extreme risks were taken into account. This includes events that originate outside the farm-gate (for example, the unexpected closing of a road, changes in the regulations surrounding pesticides, etc.), as long as they have an impact in farmer income (through costs and/or sales).

Considering that the agriculture sector has cyclical variations, this work only considered the risk associated with extreme and systemic events that affect farmer incomes. The extreme and systemic events were defined as those that produce more than one standard deviation from the average or the historical trend. Income reductions less than one standard deviation (around 10\%) were not considered. Thus, limitations of this methodology include: (i) not evaluating impacts across the supply chain (only on-farm); (ii) it is influenced by recent events (drought, road closures) that are more clear in the memory of the stakeholders, specialist and survey responders, versus events that have happened in the longer past; and (iii) not being able to ensure the correct interpretation by participants of the definition of risk, therefore referring to structural limitations (and not to unexpected adverse events).

The management of extreme agriculture risks requires different strategies, instruments, and has to acknowledge the differences in risks and stakeholders (Fig. 2). In order to reduce sector losses in an aggregate way, all extreme risks must be considered using different risk management strategies and instruments. The main management instruments available for the public sector can be summarized in investments, technical assistance and public policy actions. The different agriculture risk management actions can be grouped in the following broad strategic pillars.

Mitigation: actions that happen before the event (ex-ante) to prevent, reduce or eliminate the occurrence of extreme events or their negative economic impact on agriculture production, markets or enabling environment, such as infrastructure, animal and plant health, agroclimatic information systems, etc. Transfer: actions to transfer risks to a third party, by paying a cost (premium). Examples include financial instruments such as

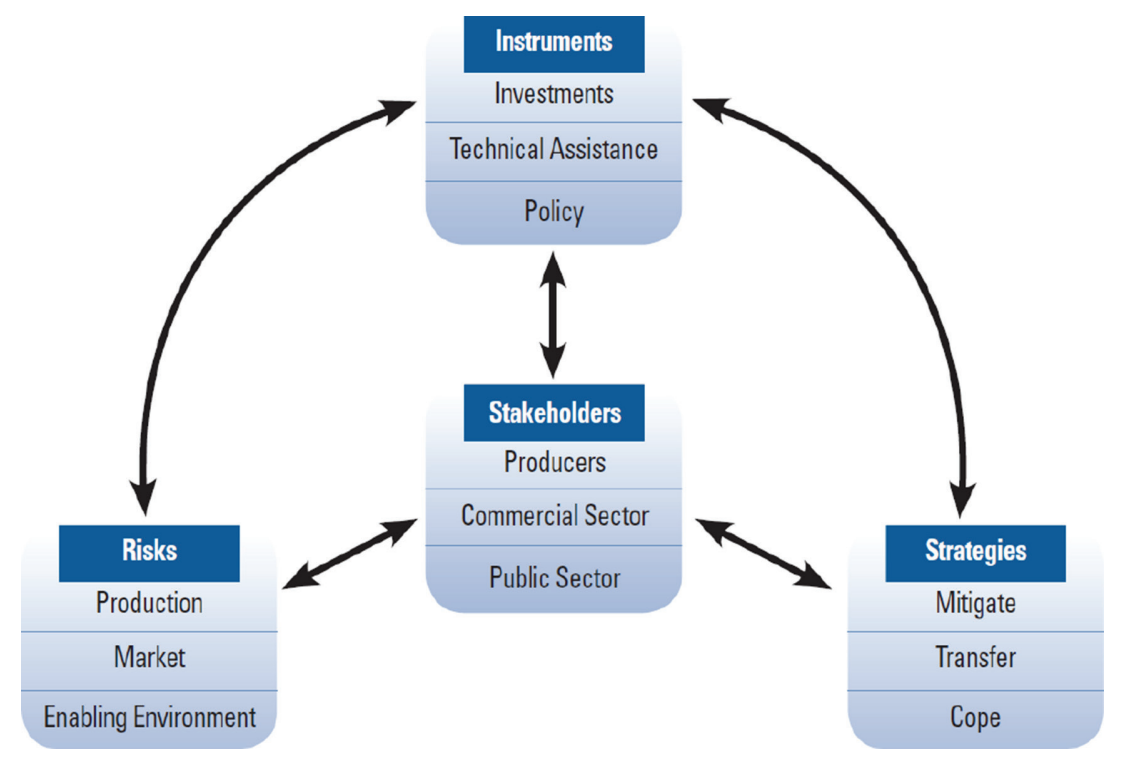

Figure 2: Integrated vision for Agriculture Risk Management (World Bank [5]). 
insurance, reinsurance, derivatives, etc. Response: actions that happen during or after an event (expost), geared towards rebuilding or compensating for losses caused by the event. Examples include emergency assistance to farmers, debt restructuring, infrastructure reconstruction, etc. An important response action that occurs ex-ante is the strategic planning or contingency planning, where response mechanisms are designed a priori in order to respond more effectively and efficiently after the event (ex: contingency plans for combating fires or for the control of disease outbreaks).

The rapid review of extreme agriculture risk management policies and programs was divided in five stages, which occurred over a period of 7 months. The Stages included: (i) the identification of the main risks and the specialists to be consulted, (ii) the literature review of recent studies on risks and the related federal-level public policies and programs; (iii) undertaking a national survey on agriculture risk perception from the sector; (iv) undertaking an event to consult with sector specialists (identified in Stage 1); and (v) systematizing the results.

\section{RESULTS}

The final results were a synthesis of the survey, of the workshop and the validation. After the validation with different institutions, the results were systematized in order to obtain a synthesis of the perceptions. The divergent results, when consensus did not happen, were eliminated. That synthesis of results, in particular during the workshop and validation, took into consideration the review of the 25 main public policies and programs.

Although there is a great number of public policies and programs in Brazil, there are gaps and opportunities. The mitigation strategy is the most representative in terms of number of public policies and programs. The predominance of mitigation is aligned with any risk management strategy. However, there are many important opportunities in the transfer and response strategies. In the case of response, specifically in cases of low frequency and high impact risks, such as sanitary problems not yet present in Brazil, the country has a relatively low number of contingency plans.

The public policies and programs mapped do not cover all losses from small and medium size farmers in an integrated manner. Larger commercial farmers have access to sophisticated financial instruments to cover price and insurance that small and medium size farmers do not. Family farmers depend on public programs where farmers receive income compensation for losses above $50 \%$ of expected yields, and even then, they do not get to cover all farm-level losses. Other public programs only cover the cost of credit, but do not compensate for the farmer income loss.

The operation of programs is complex and needs more coordination. The integration of price risk programs with the insurance programs can and should result in the protection of farmers' income. However, these programs depend on different institutions, and are implemented by different intermediaries, arriving through different vehicles to farmers.

In order to avoid duplication of actions - and looking to maximize services and coverage to improve farmers' income - an inter institutional coordination among the different programs is key to achieve more efficiency and effectiveness in the operation. Extreme risks linked to production management can be as important as other more 'traditional' agriculture risks, like weather and sanitary issues.

Risks associated to infrastructure and logistics are a priority for the sector. The sectoral vision shows that infrastructure and logistics risks have a relatively larger impact on the economy and a relatively lower level of public policy support in relation to other risks considered (Fig. 3 and Table 2). Nevertheless, the risks associated to extreme weather events were 


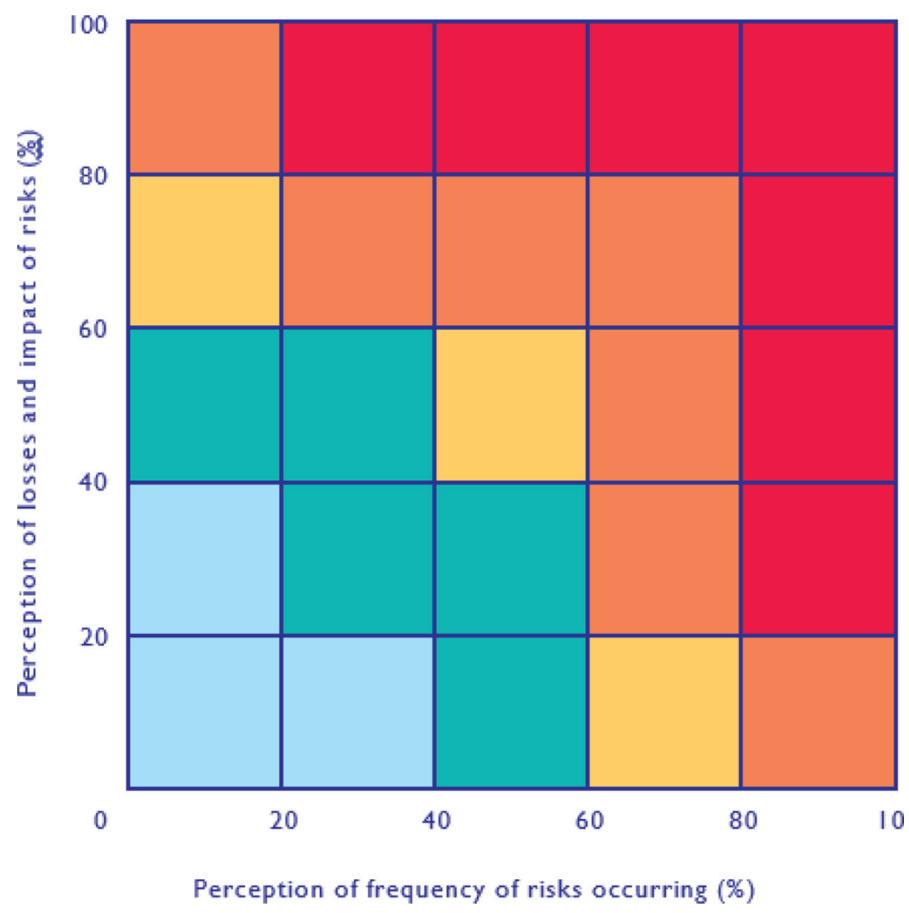

Figure 3: Perception of the impact and frequency (severity) of extreme agriculture risks.

Table 2: Perception of specialists regarding the extreme risk dimensions addressed in the study and their degree of support from current federal-level public policies in Brazil (Technical workshop, 2014).

\begin{tabular}{|c|c|c|c|}
\hline \multirow{2}{*}{$\begin{array}{l}\text { PUBLIC POLICY } \\
\text { SUPPORT }\end{array}$} & \multicolumn{3}{|c|}{ IMPACT OF RISKS } \\
\hline & LOW & MODERATE & HIGH \\
\hline HIGH & & $\begin{array}{l}\text { - International Trade } \\
\text { - Credit }\end{array}$ & \\
\hline MEDIUM & & $\begin{array}{l}\text { - Reg. framework } \\
\text { - Nat. Res. and Prod. Mgmt } \\
\text { - Market }\end{array}$ & $\begin{array}{l}\text { - Animal Health } \\
\text { - Plant Health }\end{array}$ \\
\hline LOW & & - Weather & $\begin{array}{l}\text { - Logistics and } \\
\text { infrastructure }\end{array}$ \\
\hline
\end{tabular}

considered as the second most important by specialists, receiving a classification of "very high', as well as the credit and commercialization risks.

For all the extreme agriculture risk dimensions, opportunities were identified in order to improve current federal-level public policies and programs. Integration was the main subject of the discussions. An important conclusion, backed by specialists, was that, although gaps exist, Brazil currently has a series of good risk mitigation mechanisms, average risk transfer 
mechanisms, and a lack of risk response mechanisms - however, not being able to address each one of them in an isolated fashion.

According to the specialists who attended the workshop, all extreme agriculture risks are interrelated. During the workshop, the relationships among risks were identified (Fig. 3 ), including the intensity and the direction of these existing relationships (influences) among risks. It is clear that the credit risk is influenced by most other risks. Therefore, credit can serve as a tool to promote the integrated management of other risks, promoting/incentivizing farmers to adopt best practices and technologies to reduce the probability of future loses. The reduction in the credit and trade risks requires the management of multiple agriculture risks. The relationships among agriculture risks (Fig. 4) show that credit and trade risks (price) have a high dependency on other risks.

Weather risks have an impact on other risks, and therefore, deserve special attention. From consultations with specialists, it was clear that weather risks do not only impact agriculture production risks, but also risks related to logistics and infrastructure, prices and/or food quality). Also, changes in the regulatory framework have an impact on other risks, as well as on the same public policies and programs that support the management of those same risks.

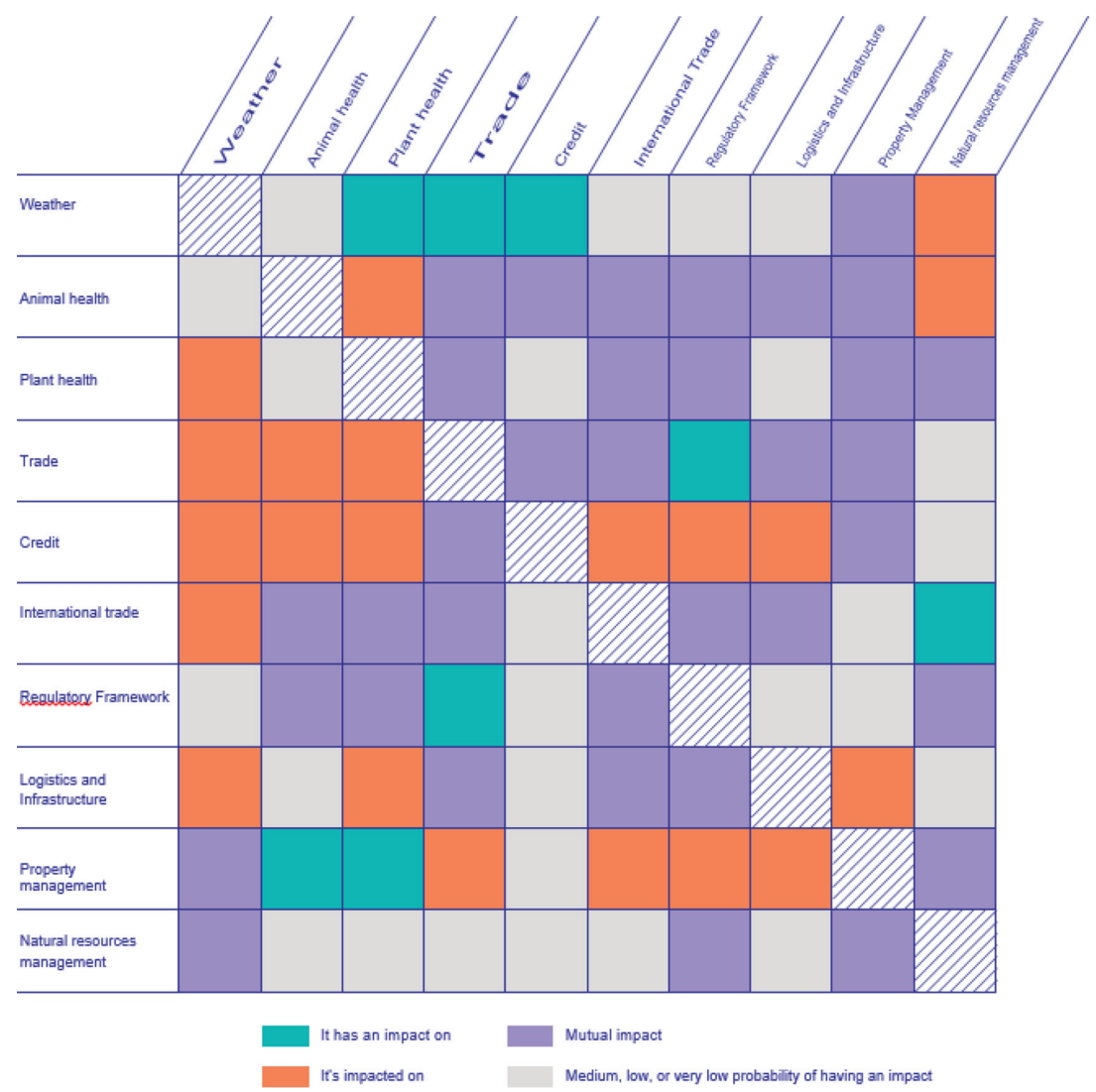

Figure 4: Relationships among the different agriculture risk dimensions in Brazil (source: author's calculations based on electronic survey, 2014). 
It is important to note that beyond the direct impact established by the specialists, the relationships among these risks can create feedback loops in the system, resulting in several orders of impacts beyond the initial one. The work done did not identify such possible feedback loops in the risks interrelationships, but it was clear that they do exist.

\section{CONCLUSIONS AND RECOMMENDATIONS}

Brazil has a great diversity of policies and programs that support the agriculture sector in a counter-cyclical fashion, some of them being international success cases for both developing and developed countries. However, it is clear that there are several opportunities to improve the existing policies and programs, in particular in relation to their integration, which will not necessarily produce additional public spending, but can result in a better enabling environment for agriculture production, ensuring a more robust and sustainable sector growth.

According to the agriculture risk policies and program mapping, there are gaps in the management of extreme risks, in particular the lack of availability of contingency planning. In order to be able to manage risks in an integrated manner, the set of public policies and programs must consider mitigation, response and transfer strategies. Studies such conducted by the World Bank [6] show that although mitigation strategies, on average, have a higher economic return than transfer or response strategies (for each $\mathrm{R} \$ 1$ invested in mitigation, this saves up to $\mathrm{R} \$ 7$ in emergency response), there are cases in which mitigation and transfer are not optimal strategies. In Brazil, there are extreme risks and events (for example the sanitary events that occur in neighboring countries) that are not well known, but that have a potential for large economic losses for farmers. Although the mapping of those events and the adoption of mitigation actions could be recommended, it is always essential to adopt contingency plans. The actions of some of the northeastern states (Pernambuco and Ceará) in the preparation of state-level agriculture preparation plans for droughts are examples of such contingency planning in order to avoid future losses in the sector.

There is an insufficient level of support from public policies and programs for the management of risks such as: (i) logistics and infrastructure; and (ii) property and natural resources management. An agenda for the future needs to include the management of logistics and infrastructure risks and property and natural resources management risks (mitigation and adaptation actions) in order to reduce loses and the uncertainty of the sector. The creation of an environment and discussion forums among the various stakeholders will enable a qualitative leap towards an integrated management of those risks.

An integrated management of extreme risks by the government requires not only coordination among the different policies and programs, but also among the different levels of government. The current work focused on federal-level public policies and programs, but the coordination of federal actions with state and municipal agriculture risk initiatives is key, such as the coordination among Ministries and Agencies. In this work it was not possible to map subnational initiatives, but initiatives such as the state-level agriculture insurance premium subsidy that complements the federal-level subsidy and the preparation of municipal and state-level agriculture risk management plans (such as the experience of Pernambuco and Ceara) should be part of an agenda for the future.

A basic component for an appropriate management of extreme risks is to have policies and programs within a long-term strategic planning context. In the weather risk panel, although being mainly a technical group, the importance of multiannual agriculture plans for agriculture risk management strategic planning. Furthermore, in most validation meetings the recommendation extended beyond risk management, being clear the need of an agriculture 
law (as the Farm Bill of the United States), with a minimum horizon of five years, integrating issues related to the eight risk areas of this work, as well as other rural development and social mobility issues of the agriculture sector.

International experience and the number and diversity of existing public policies and programs in Brazil show that integration needs to happen gradually. Usually, in other countries, risks are managed in an integrated way by the private sector. As with most high-income countries, risk management policies and programs: (i) focus on farmers' income as a final objective; (ii) seek market solutions with public-private partnerships to adapt to producer demands and leverage private financing for risk management; and (iii) focus on coordination and information sharing among different participating institutions based on rural producers.

In order to promote and implement a long-term integrated management of risks, it is recommended to establish a risk management unit with the qualified staff and a national plan that would give sustainability for a permanent integrated vision. That agriculture risk management unit must be geared towards implementing a national multiannual plan, which can begin by the implementation of the six macro-objectives identified in this work and listed below.

\subsection{An integrated agriculture risk management information system}

Brazil already has several agriculture risk management information systems, some of them already integrating information on several risks. Embrapa, the National Meteorological Institute (INMET), and the Climate Forecasting and Studies Center (CPTEC/INPE) have information systems and probabilistic analysis about weather risks at the municipal scale, which are not being utilized to the fullest by farmers. These systems, beyond their main objective which is to support farmers production decisions in relation to the weather, they could be more integrated with other existing systems that are not yet geared towards risk management, such as market information, natural resources management, animal and plant health and logistics.

\subsection{Integrated technology development and transfer system for risk management}

The adoption of loss reduction technologies depend on the innovation and transfer capacity and the integration in the management of multiple risks. Today, in Brazil, the agriculture technology research and development system does not have tools for analyzing risks in an integrated way (see section 4.1 above), nor the capacity to interact with farmers for an integrated management of risks, in particular with family farmers.

It is necessary to seek the structuring of rural technical assistance ATERs, in particular in the north and northeast regions, promoting qualified staff, as well as the integrated approach towards managing risks in the sector. Although in Brazil there are some systems dedicated to technology transfer, such as the Information Technology Agency of Embrapa (Ageitec), it is not integrated and could be better utilized.

\subsection{Integrated agriculture risk transfer system}

There is an opportunity in Brazil to transfer a higher level of production risks through public-private partnerships. Agriculture insurance coverage provided by private insurances reaches $8 \%$ of cultivated area according to Buainain and Vieira [7]. However, the public 
insurance and income compensation programs represent more than that covered by private insurance firms. These income compensation programs do not transfer risks outside the public sector nor outside the country. The federal government absorbs $100 \%$ of the risks of catastrophic events, given that the premiums paid by beneficiaries are not enough to cover the payouts (the cost of the programs are paid in large part by the federal, state and municipal governments).

Furthermore, the rural insurance and price guarantee systems could be linked to offer an income insurance product to the farmer. The risks linked to price and pest/disease outbreaks are excluded from insurance programs and have particular policies and programs. The specialists who were consulted identified an opportunity to coordinate the insurance, price and animal and plant health programs to allow to have income insurance products for farmers.

\subsection{Integrated agriculture logistics and rural infrastructure planning}

The agrologistics and infrastructure system of Brazil suffers from extreme risks that could be reduced by the sharing of information and by the coordination with the management of other risks. These extreme risks cause on-farm losses, increasing the cost of transport and logistics, especially for farmers that do not have storage capacity. There are also risks along the supply chain given the uncertainty and seasonality of logistics costs, in particular transport. The bottlenecks in the logistics system (roads, ports and waterways) that generate uncertainties regarding time and transport and storage costs are well known. Therefore, with the sharing of information between the logistics and the planning of harvests and trades could reduce the uncertainty for the farmer.

\subsection{Integrating weather risk management tools to natural resources management}

There is an opportunity in the short term to reduce the natural resources management risk, in particular water resources and extreme drought risk, using existing weather risk management tools in the water allocation decisions. Challenges with water management in Brazil are long-standing, as the droughts in the northeast region, and increasing, as the recent uncommon drought in the southeast and the centerwest regions. Beyond the climatic risk, which depends on the management of an efficient and accessible information system, the risk of natural resources management persists given that the water allocation system do not use risk analysis tools such as the Agroclimatic Risk Zoning (ZARC) and the climate change models in decision making.

4.6 Integrating agriculture risk management into international trade promotion and monitoring

International agriculture trade policies in Brazil are not very well integrated to the agriculture risk management policies and programs. In particular, there are short term opportunities for more and better integration of animal and plant health policies with those of international trade, facilitating initiatives such as regional sanitary certification and their recognition in markets. There are also opportunities to reduce farmer losses due to the closing of international markets, coordinating international trade with trade risk management programs (price guarantees) and production (insurance). These agriculture risk management integration measures, along with international trade policies, could result in a more assertive participa- 
tion of Brazil in international trade negotiation forums. In other words, Brazil could change its current position as a rule taker for rule maker in the international stage and a better management of agriculture risks can change that position.

\section{REFERENCES}

[1] De Nys, et al., Drought Impacts and Cost Analysis for Northeast Brazil, CRC Press, Boca Raton, Florida, 2016.

[2] MB Agro Consulting. Seguro Agrícola no Brasil. Presented at the Agriculture Insurance Forum of Brasil, 2012.

[3] Nogueira, JM. \& Doliveira, CFD., Cost-benefit analysis of foot-and-mouth disease control strategies. Evaluation of a national operating program and assessment of a proposed alternative regional control program: Lessons from Brazilian experiences. Presented at the Sociedade Brasileira de Economia, Administração e Sociologia Rural Conference, July 2012.

[4] Website of the Senate of the Brazilian Congress. Available at http://www.senadorhumberto.com.br/governo-disponibiliza-r-27-bilhoes-para-combater-a-seca-no-nordeste/ (accessed 21 January 2017).

[5] World Bank. Agriculture Risk Management Framework. Available at http://www. agriskmanagementforum.org/content/ag-discussion-paper-10-agricultural-sector-riskassessment-methodological-guidance-practitio (accessed 21 January 2017).

[6] World Bank. Natural Disasters: Counting the Costs. Available at http://siteresources. worldbank.org/INTEAPHALFYEARLYUPDATE/Resources/550192-1300 567391916/EAP_Update_March2011_japan.pdf (accessed 21 January 2017).

[7] Buainain, AM. \& Vieira Junior, PA., Seguro Agrícola no Brasil: desafios e potencialidades. Revista Brasileira de Risco e Seguro, Rio de Janeiro, 7(13), pp. 39-68, 2011. 